\title{
Research Paper: Interaction of Sodium Valproate With Low-Frequency Electrical Stimulation During Kindlingn
}

\author{
Raha Zalkhani $^{1^{*}}$ (D), Ahmad Ali Moazedi' ${ }^{1}$ (D), Zohreh Ghotbeddin² ${ }^{2}$, Mahdi Pourmahdi³ ${ }^{3}$
}

1. Department of Biology, Faculty of Science, Shahid Chamran University of Ahvaz, Ahvaz, Iran.

2. Department of Basic Sciences, Faculty of Veterinary Medicine, Shahid Chamran University of Ahvaz, Ahvaz, Iran.

3. Department of Food Hygiene \& Quality Control, Faculty of Veterinary Medicine, Shahid Chamran University of Ahvaz, Iran

\begin{tabular}{|l|l|}
$\begin{array}{c}\text { Use your device to scan } \\
\text { and reat the article online }\end{array}$ & $\begin{array}{l}\text { Citation: Zalkhani, R., Moazedi, A. A., Ghotbeddin, Z., \& Pourmahdi M. Interaction of Sodium Valproate With Low-fre- } \\
\text { quency Electrical Stimulation During Kindlingn. Basic and Clinical Neuroscience, 11(6), 831-840. http://dx.doi.org/10.32598/ } \\
\text { bcn.11.6.1392.2 }\end{array}$ \\
& dolo http://dx.doi.org/10.32598/bcn.11.6.1392.2
\end{tabular}

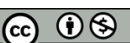

Article info:

Received: 18 Jun 2019

First Revision: 10 Jul 2019

Accepted: 17 Feb 2020

Available Online: 01 Nov 2020

Keywords:

Kindling, Seizure, Valproate, Electrical stimulation

\section{A B S T RA C T}

Introduction: The interaction between antiepileptic drugs and brain electrical stimulation is a potential therapy to control seizures in patients with pharmacoresistance to drugs. So, the present study aimed to design to determine the effect of a subeffective dose of sodium valproate combined with low-frequency electrical stimulation during kindling.

Methods: One tripolar electrode was implanted stereotactically in the CA1 hippocampus of male Wistar rats. One week after surgery, the rats were kindled by electrical stimulation of hippocampus in a rapid manner (12 stimulations/day) for 6 days with sodium valproate alone or combined with low-frequency electrical stimulation (four packages contained 200 monophasic square wave pulses of $0.1-\mathrm{ms}$ duration at $1 \mathrm{~Hz}$, immediately after kindling stimulations). The duration of afterdischarge, maximum latency to stages 4 and 5, and the maximum duration of these stages were recorded by electromadule during kindling.

Results: Application of sodium valproate with low-frequency electrical stimulation caused a reduction in cumulative afterdischarge duration. The maximum latency to the onset of stage 5 seizure increased after sodium valproate application alone, without having a significant effect on the fourth stage. Our findings showed reductions in the seizures duration and increasing in the latency times of both stages after the application of sodium valproate with low-frequency electrical stimulation.

Conclusion: It seems that usage of sodium valproate with low-frequency electrical stimulation during kindling was more effective to suppress the epileptic activity than its administration alone and may have a critical role on the antiepileptic effects of sodium valproate.

\section{* Corresponding Author:}




\section{Highlights}

- Hippocampal rapid kindling decreased seizure latency and increased seizure duration of stages 4 and 5.

- The latency time of stages 4 and 5 seizure increased after the application of sodium valproate combined with lowfrequency electrical stimulation.

- The seizure duration of stages 4 and 5 seizure declined after the application of sodium valproate with low-frequency electrical stimulation.

\section{Plain Language Summary}

Some patients do not successfully respond to the antiepileptic drugs in refractory epilepsy. The interaction between antiepileptic drugs and brain electrical stimulation is a potential therapy to control seizures in patients with pharmacoresistance to drugs. Our findings demonstrated that the application of sodium valproate with low-frequency electrical stimulation may have a critical role in the antiepileptic effects of sodium valproate.

\section{Introduction}

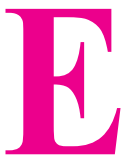

pilepsy is a chronic disorder of the brain which affects approximately 50 million of the world population (Pitkänen et al., 2016). It is defined as a condition by recurrent, unpredictable, and unprovoked epileptic seizures that can be associated with a variety of mental and physical functions (Goldenberg, 2010). Imbalances of excitation/inhibition functions are related to several neurological disorders like epilepsy (Bonansco \& Fuenzalida, 2016).

Temporal lobe epilepsy is the most prevalent form of drug-resistant epilepsy among adults (Bonansco \& Fuenzalida, 2016). A variety of animal models have been suggested to analyze temporal lobe epilepsy; however, kindling is the most commonly used model in rodents to study epileptogenesis, electroencephalographic, and behavioral features of seizures which are resembled temporal lobe epilepsy in humans (Kandratavicius et al., 2014). Kindling is induced by repeated electrical stimulations at limbic brain regions such as the amygdala and hippocampus with an initial subconvulsive current to evoke afterdischarge in the electroencephalographic (Kalynchuk, 2000). The afterdischarge is defined as discharges of neural impulses with a frequency of at least $1 \mathrm{~Hz}$ and amplitude of at least twice the baseline observed after the termination of the hippocampal electrical stimulation (Löscher, Potschka, Wlaź, Danysz, \& Parsons, 2003).

Drug therapy is the mainstay of treatment for most epileptic patients. Until the 1990 s, there were a hand- ful of antiepileptic drugs available to treat several seizure disorders. Now, there are over 20 different drugs to treat seizures. However, the efficacy of most existing drugs is only up to $70 \%$ and the rest continue to experience seizures, illness, and risk of death (Asgari et al., 2014; Telfeian, Celix, \& Dichter, 2005). As an important issue, medically-resistant epilepsy can be identified as uncontrollable epilepsy after the usage of 2 appropriate doses of antiepileptic drugs (Krauss \& Sperling, 2011). Despite advances in pharmacotherapy for epilepsy, the prevalence of intractable epilepsy, particularly temporal lobe epilepsy, is very high and most of them are treatment-resistant epilepsy. On the other hand, it has been reported that removing the epileptogenic region of the brain as another possible treatment may be effective only in a small percentage of patients with refractory epilepsy which is accompanied by several serious complications (West, Nolan, \& Newton, 2016). As a result, there is an urgent need to develop alternative therapies like deep brain stimulation. Previous clinical and experimental studies have both demonstrated that low-frequency electrical stimulation (LFS) $(0.5$ to $10 \mathrm{~Hz})$ exert seizure shortening and suppressive effects with the advantages of reversibility and adjustability (Kuang et al., 2017; Mohammad-Zadeh et al. 2007; Schulze-Bonhage, 2017; Schrader et al., 2006; Toibaro et al., 2012). Low-frequency stimulation may be more advantageous than high-frequency one due to the smaller current requirement and subsequently lower risk of tissue damage. The cellular consequences that underlie the protective effect of LFS and stimulation protocols are not clear yet; however, some experiments revealed that activation of GABA receptors by 
LFS may involve in the antiepileptic effects (Asgari et al., 2014; Kile, Tian, \& Durand, 2010).

Valproate, a branched-chain organic acid, is widely used as an antiepileptic drug in the treatment of both generalized and partial seizures in adults and children (Goldenberg, 2010). Investigations and clinical experiments evaluated the new application of this drug for preventing other disorders, including migraine headaches and bipolar disorders (Chiu, Wang, Hunsberger, \& Chuang, 2013; Hoffmann, Akerman, \& Goadsby, 2014). It exerts its antiepileptic effects through several neurochemical and neurophysiological mechanisms such as GABAergic activity (gamma-aminobutyric acid), reduction in excitatory neurotransmission, and modification of monoamines of neuronal tissue that might explain its efficacy to suppress epilepsy and other brain disorders (Löscher, 2002).

A lot of experimental evidence shows that valproate increases Gamma-Aminobutyric Acid (GABA) receptor function directly through interaction with the receptors or indirectly by increasing the level of the GABA by deactivating GABA transaminase enzyme and blocking the reuptake of GABA into glia and nerve endings in some specific brain regions which are involved in the generation and propagation of seizure. GABA as the most important inhibitory neurotransmitter in the mammalian central nervous system declines the excitability of neurons (Löscher, 1999; Whitlow, Sacher, Loo, Nelson, \& Eskandari, 2003). On the other hand, some studies suggest that a combined therapy by LFS and some antiepileptic drugs can increase the efficacy of each treatment and may be a suitable solution for treating patients who are medically resistant to epilepsy (Asgari et al., 2014).

Therefore, the present study was designed to investigate the possible interaction between sodium valproate and LFS on seizure severity during kindling.

\section{Methods}

\subsection{Study animals}

Adult male Wistar rats $(200 \pm 20 \mathrm{~g})$ were placed in cages under standard laboratory conditions (ambient temperature $230 \mathrm{C}-250 \mathrm{C}, 12 / 12 \mathrm{~h}$ light/dark alternate cycle with lights on between 7:00 AM and 7:00 PM, and free access to food and water).

All stages of the experiment were designed and executed in accordance with the instructions of the Ethics
Committee of laboratory animals at Shahid Chamran University of Ahvaz, Ahvaz City, Iran, and were in compliance with the NIH guide for the care and use of laboratory animals.

\subsection{Drugs and treatments}

Sodium valproate was purchased from Sigma and dissolved in physiological saline $(0.9 \%$ sodium chloride). The drug was injected intraperitoneally (IP) at the doses of 100 and $200 \mathrm{mg} / \mathrm{kg}$ and the control group received $0.9 \%$ saline in a volume of $1 \mathrm{~mL} / \mathrm{kg}$.

\subsection{Surgery}

All rats were anesthetized by a ketamine/xylazine mixture $(100 / 10 \mathrm{mg} / \mathrm{kg}$, IP). One tripolar stainless electrode (A.M. system, Inc., USA) (bipolar for stimulating and monopolar for recording) was implanted stereotactically (Stoelting Co., USA) in the CA1 hippocampus of the right hemisphere of rats (coordinates from bregma: anteroposterior: $2.5 \mathrm{~mm}$; lateral: $1.8 \mathrm{~mm}$; vertical: 2.8 below the skull) using coordinates of Paxinos and Watson atlas (Paxinos \& Watson, 1998). One monopolar electrode was used as a ground and reference electrode and attached to the skull with stainless steel crew. The electrodes were connected to pins and inserted into a socket and fixed in the skull with acrylic dental cement. Then they were placed in individual cages (Mohammad-Zadeh et al., 2007).

One week after surgery, to determine the afterdischarge threshold, a $3-\mathrm{s}$ train of $50-\mathrm{Hz}$ monophasic square pulses of 1-ms duration was initially applied at $30 \mu \mathrm{A}$ and it was increased by $10 \mu \mathrm{A}$ gradually with 10 -minute intervals. The minimum intensity that was sufficient to induce at least $8 \mathrm{~s}$ afterdischarge, was selected as the afterdischarge threshold and was used for kindling stimulations (Mohammad-Zadeh et al., 2007).

One day following afterdischarge threshold determination, the rats were kindled by electrical stimulations (a 3-s train of 50-Hz monophasic square waves [1 ms] at afterdischarge threshold) of CA1 hippocampus in a rapid manner (12 stimulations/day, at inter-train intervals of $10 \mathrm{~min}$ ) for 6 days with an electro modulator device (Science beam Co., Tehran, Iran) which was connected to a computer for monitoring epileptiform afterdischarge durations using the e-probe software program. In the saline-kindled-LFS (K.LFS) group, the animals received four packages of LFS daily (each package consisted of 200 monophasic square pulses, $0.1-\mathrm{ms}$ pulse duration at $1 \mathrm{~Hz}$ with the AD threshold 
intensity) with 5 minutes interval immediately after termination of kindling stimulation (Mohammad-Zadeh et al., 2007).

\subsection{Experimental design}

Animals were divided into 6 groups. The salinekindled (S.kindled) group was selected as the control group and received saline 15 minutes before kindling stimulation (I). The saline-kindled-LFS group (K.LFS) was injected with saline 15 minutes before kindling stimulations and LFS was applied daily after the termination of kindling stimulation (II). Also, there are drug-kindled groups (Drug100.kindled and Drug200. kindled). In these groups, sodium valproate (100 and $200 \mathrm{mg} / \mathrm{kg}$ ) was injected 15 minutes before kindling stimulations (III and IV) and drug-kindled-LFS groups included Drug100.kindled.LFS and Drug200.kindled. LFS which were received drug and LFS, respectively before and after kindling stimulations (V and VI).

The progression of kindling was monitored by recording the duration of afterdischarge and the behavioral seizure stages following stimulations according to Racine's classification (Racine, 1972): stage 1, facial clonus; stage 2, head nodding; stage 3, forelimb clonus; stage 4 , rearing and bilateral forelimb clonus; stage 5 , rearing and falling. The recorded parameters were afterdischarge duration, the maximum latency to the onset of stages 4 and 5, and the maximum duration of stages 4 and 5. Seizure duration was measured from the beginning until the end of seizure behavior. The duration of afterdischarge was measured from the onset of the stimulation until the end of afterdischarge.

\subsection{Histology}

At the end of the experiments, to verify electrode positions, the animals were killed and their brains were removed, sectioned, and examined under a microscope. In case of any abnormality, the data from that particular animal were excluded from the final analysis.

\subsection{Statistical analysis}

The values are presented as Means \pm SEM. A repeated measures ANOVA was used to determine changes in cumulative afterdischarge durations (the sum of after discharge durations recorded after 12 daily stimulations). The level of significance was set at 0.05 for all statistical tests. All statistical assessments were performed using SPSS V. 21.

\section{Results}

Effects of LFS application on hippocampus kindling acquisition parameters.

A repeated measure with post hoc Tukey test showed that LFS application had a significant effect on the progression of cumulative afterdischarge durations following the kindling stimulations in the last three days of kindling, respectively with $\mathrm{P}$ values of $0.043,0.017$, and 0.003 (Figure 1). However, there was no significant difference in the maximum latency to the onset of stage $4(\mathrm{P}=0.325)$ but the duration of this stage significantly decreased compared to that in the S.kindled group $(\mathrm{P}=0.001)$. Also, we did not have stage 5 of seizure in the K.LFS group, indicating the anticonvulsant effect of LFS (Figure 2 and Table 1).

3.1.Effects of sodium valproate at two doses $(100$, $200 \mathrm{mg} / \mathrm{kg}$ ) on hippocampus kindling acquisition parameters

We also studied the effects of intraperitoneal injection of sodium valproate on cumulative afterdischarge durations. As shown in Figure 3, there was a significant difference in cumulative afterdischarge durations between animals that received $100 \mathrm{mg} / \mathrm{kg}(\mathrm{P}=0.032)$ and $200(\mathrm{P}=0.000) \mathrm{mg} / \mathrm{kg}$ sodium valproate and saline-injected animals. Also, the injection of sodium valproate at $200 \mathrm{mg} / \mathrm{kg}$ dosage increased the maximum latency to the onset of stage 4 and decreased the maximum duration of this stage $(\mathrm{P}=0.000)$ (Figure 2 and Table 1). However, it did not have any significant effect on these parameters at a lower dose and could not prevent the occurrence of stage 5 .

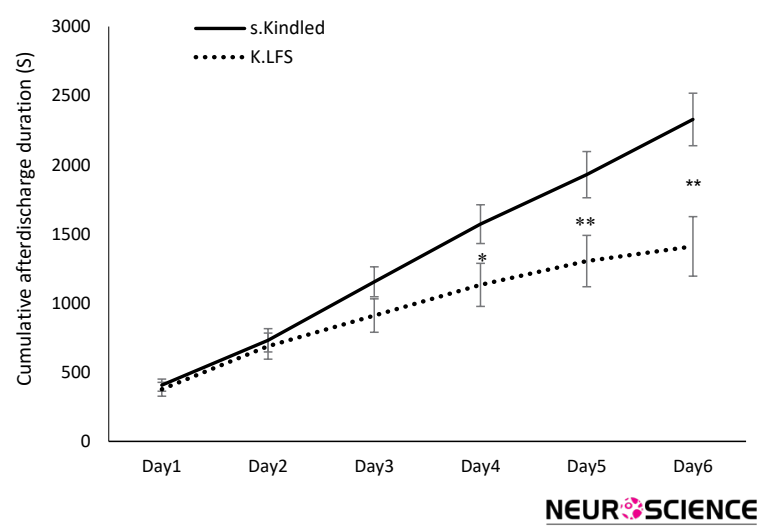

Figure 1. Effect of Low-Frequency electrical Stimulation (LFS) application on the progression of cumulative afterdischarge durations

Data are presented as Mean \pm SEM. ${ }^{*} \mathrm{P} \leq 0.05$ and ${ }^{* *} \mathrm{P} \leq 0.01$ compared to the saline-kindled (S.kindled) group. 

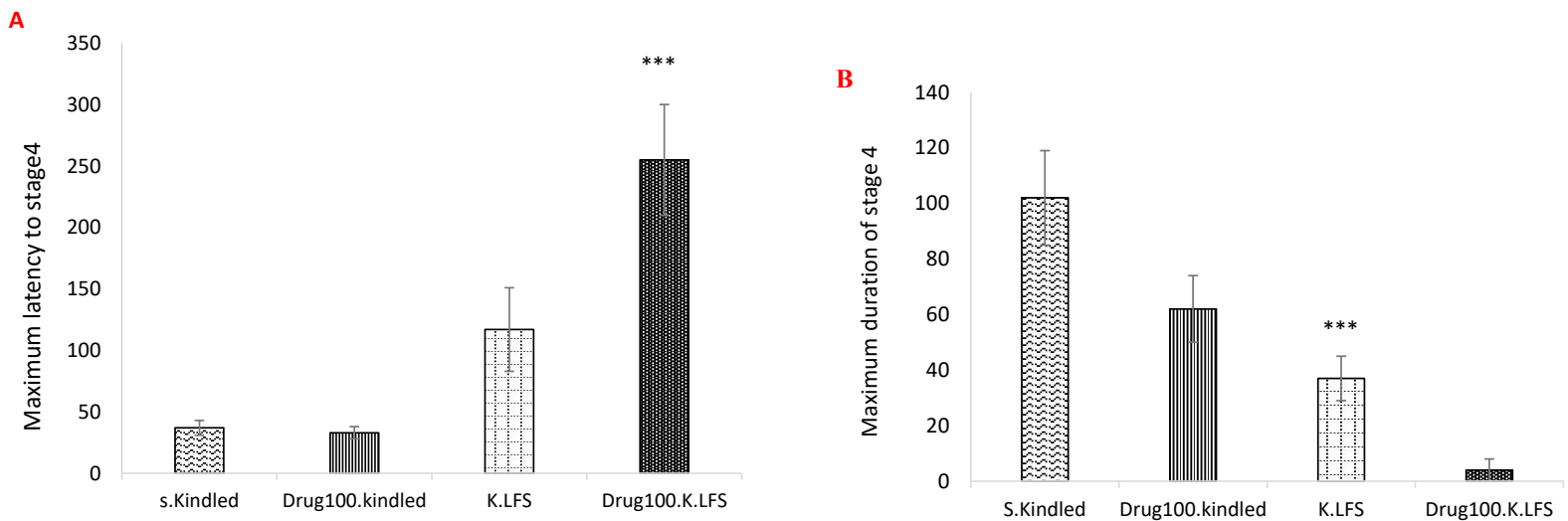

NEUR SCIENCE

Figure 2. Effects of sodium valproate and low-frequency electrical stimulation alone and combined, on hippocampus kindling acquisition parameters

A: Maximum latency to stage 4; and B: Maximum duration of stage 4

Data are presented as Mean $\pm \mathrm{SEM} ;{ }^{*} \mathrm{P} \leq 0.05,{ }^{* *} \mathrm{P} \leq 0.01$, and ${ }^{* * *} \mathrm{P} \leq 0.001$ compared to the saline-kindled (S.kindled) group.

3.2. Effects of sodium valproate combined with low-frequency electrical stimulation on hippocampus kindling acquisition parameters

Sodium valproate $(100 \mathrm{mg} / \mathrm{kg} \mathrm{IP})$ alone reduced the duration of cumulative afterdischarge and stage 5 of seizures and increased the latency to the onset of this stage without a significant effect on the onset and duration of stage 4 .

To examine the interaction between LFS and sodium valproate, LFS was applied with sodium valproate at $100 \mathrm{mg} / \mathrm{kg}$ (Figure 4) like $200 \mathrm{mg} / \mathrm{kg}$ (Figure 5) along with LFS caused a significant decrease in cumulative afterdischarge duration compared to that in the S.kindled group during three last days of kindling stimulation. Also, combined therapy significantly

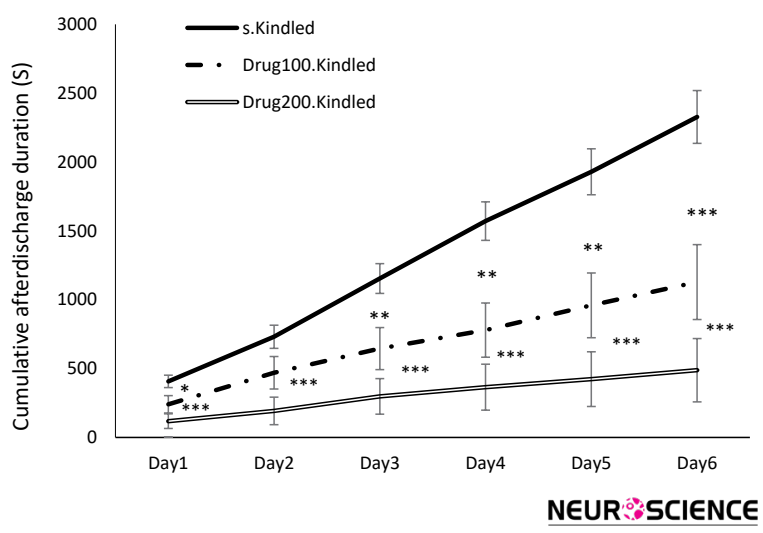

Figure 3. Effects of sodium valproate injection at two doses (100 and $200 \mathrm{mg} / \mathrm{kg}$ ) on afterdischarge durations

Data are presented as mean $\pm S E M$. * $\mathrm{P} \leq 0.05,{ }^{* *} \mathrm{P} \leq 0.01$, and ${ }^{* *} \mathrm{P} \leq 0.001$ compared to the saline-kindled (S.kindled) group increased the maximum latency to the onset of stage 4 and decreased the maximum durations of this stage $(\mathrm{P}=0.000)$ compared to that in the S.kindled. However, its application alone had no significant effect on these parameters compared to those in the S.kindled group. Similarly, the inhibitory effects of combined application of sodium valproate and LFS on the occurrences of stage 5 was also greater than that application of each of them alone $(\mathrm{P}=0.000)$ (Figure 5 and Table 1$)$.

\section{Discussion}

According to several studies, brain stimulation reduces the frequency and severity of seizures in epileptic patients and animal models of epilepsy. However, we have few studies on the effect of the combined applica-

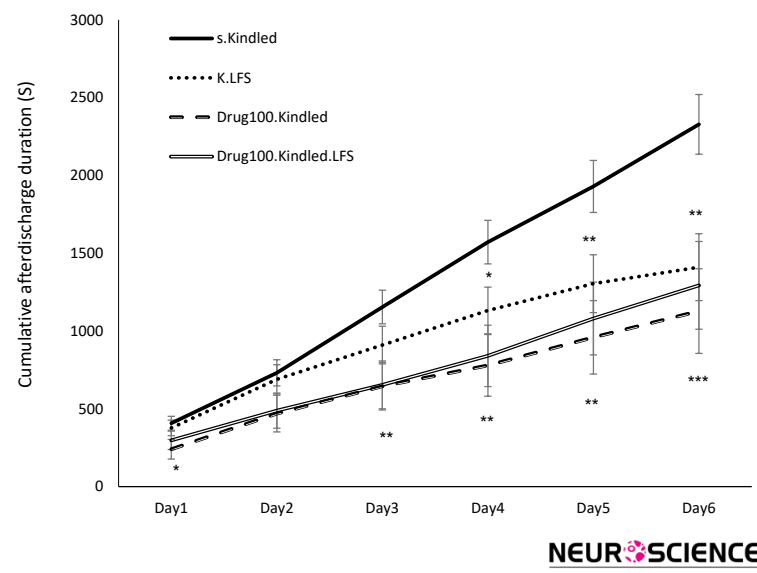

Figure 4. Effects of sodium valproate injection at $100 \mathrm{mg} / \mathrm{kg}$ on afterdischarge duration

Data are shown as mean \pm SEM. ${ }^{*} \mathrm{P} \leq 0.05,{ }^{* *} \mathrm{P} \leq 0.01$, and ${ }^{* * *} \mathrm{P} \leq 0.001$ compared to the saline-kindled (S.kindled) group. 


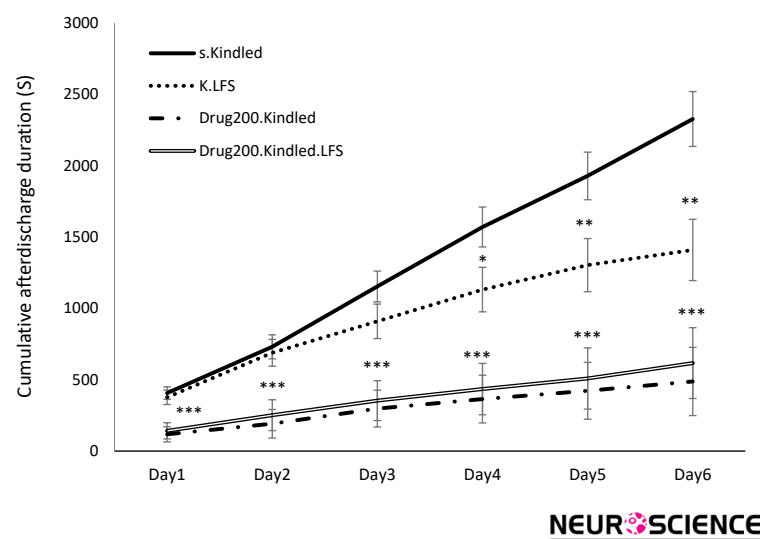

Figure 5. Effects of sodium valproate injection at $200 \mathrm{mg} / \mathrm{kg}$ on afterdischarge duration

Data are presented as mean \pm SEM. ${ }^{*} \mathrm{P} \leq 0.05,{ }^{* *} \mathrm{P} \leq 0.01$, and *** $\mathrm{P} \leq 0.001$ compared to the saline-kindled (S.kindled) group.

tion of antiepileptic drugs and brain electrical stimulation on seizure treatment (Kile, Tian, \& Durand, 2010; Kuang et al., 2017; Mohammad-Zadeh et al., 2007; Schrader et al., 2006; Schulze-Bonhage, 2017; Toibaro et al., 2012).

The results of the present study confirmed the antiepileptic effects of sodium valproate $(200 \mathrm{mg} / \mathrm{kg})$ and LFS alone during kindling acquisition. Mantovani, Moser, Haas, Zentner and Feuerstein (2009) proposed that GABA receptors were involved in CNS disorders, so, its modulation by brain electrical stimulation might be physiologically relevant. Also, Carrington, Gilby and McIntyre (2007) reported that direct LFS apply to the kindled network had a significant threshold-elevating feature. It has been shown that administration of valproate at $200 \mathrm{mg} / \mathrm{kg}$ in kindled rats increases the afterdischarge threshold by enhancing GABA turnover and reduces firing in substantia nigra pars reticulate, the main structure involved in seizure propagation, seizure control, and epilepsy-induced neuroplasticity (Löscher, Rundfeldt, \& Hönack, 1993; Loscher, 1989; Rohlfs, Rundfeldt, Koch, \& Löscher, 1996; Töllner, Wolf, Löscher, \& Gernert, 2011).

Our findings also showed that sodium valproate at 100 $\mathrm{mg} / \mathrm{kg}$ dose unlike $200 \mathrm{mg} / \mathrm{kg}$ did not have significant effects on the maximum latency to the onset and duration of stage 4 and could not prevent the occurrences of stage 5. Combination of a low dose of sodium valproate with LFS had a significant anticonvulsant effect during CA1 hippocampus kindling in rats (Figures 3, 5, and Table 1). In other words, the application of LFS with sodium valproate decreased cumulative afterdischarge duration and enhanced the maximum latency to the onset and duration of generalized seizures (stages 4 and 5) in comparison with the alone application.

In this regard, Asgari et al. (2014) suggested that a combined subeffective dose of phenobarbital and LFS could effectively modify seizures in kindled rats. Besides, a previous study by Cuellar-Herrera et al. (2010) indicated that the application of high-frequency stimulation together with a sub-threshold dose of diazepam, phenobarbital, and gabapentin, reduced the incidence of generalized seizures and mortality rate, and increased the latency time to the first generalized seizure. Also, the combination of sodium valproate with lowfrequency electrical stimulation in the CA1 hippocampus can decrease emotional disturbances induced by the kindling process (Zalkhani, Moazedi, Ghotbeddin, \& Pourmahdi Borujeni, 2020).

Table 1. Effects of sodium valproate and low-frequency electrical stimulation, alone and combined, on hippocampus kindling acquisition parameters

\begin{tabular}{|ccccc}
\hline \multicolumn{1}{c}{ Group } & $\begin{array}{c}\text { Maximum } \\
\text { Latency to the Onset Of Stage 5 }\end{array}$ & $\begin{array}{c}\text { Maximum } \\
\text { Duration of Stage 5 }\end{array}$ & $\begin{array}{c}\text { Occurrence } \\
\text { Number of Stage 4 }\end{array}$ & $\begin{array}{c}\text { Occurrence Num- } \\
\text { ber of Stage 5 }\end{array}$ \\
\hline Saline-kindled & $66.6 \pm 6.9$ & $117.57 \pm 11.8$ & $14.6 \pm 2.2$ & $7.7 \pm 2$ \\
\hline Saline-kindled-LFS & $300 \pm 0 * * *$ & $0 * * *$ & $4 \pm 1.2$ & 0 \\
\hline Drug 100.kindled & $201.6 \pm 60.3 * *$ & $32.20 \pm 20 * * *$ & $8.2000 \pm 1.0$ & $1.6 \pm 1.02$ \\
\hline Drug 200.kindled & $300 \pm 0 * * *$ & $0 * * *$ & 0 & 0 \\
\hline Drug 100.kindled.LFS & $300 \pm 0 * * *$ & $0 * * *$ & $0.6 \pm 0.6$ & 0 \\
\hline Drug 200.kindled.LFS & $300 \pm 0 * * *$ & $0 * * *$ & 0 & 0 \\
\hline
\end{tabular}

Data are presented as Mean $\pm \mathrm{SEM} ;{ }^{*} \mathrm{P} \leq 0.05 ; * * \mathrm{P} \leq 0.01$, and ${ }^{* *} \mathrm{P} \leq 0.001$ compared to the saline-kindled (S.kindled) group;

LFS: Low-Frequency electrical Stimulation. 
Our results confirmed some clinical study results. They showed that the application of deep electrical stimulation with drug therapy could also decrease the dosage of anticonvulsant drugs required to control seizures in some epileptic patients (Kerrigan et al., 2004; Vonck, Boon, Achten, De Reuck, \& Caemaert, 2002).

In contrast to the positive effects of sodium valproate with LFS, some antiepileptic drugs like phenytoin, a drug that inhibits voltage-dependent sodium currents, combined with electrical stimulation did not have any protective effect and even increased the probability of occurrence generalized seizure (Cuellar-Herrera et al., 2010).

Despite a lot of studies done on the effects of deep brain electrical stimulation on diseases, its possible mechanisms of action have not been completely clear (Mohammad-Zadeh et al., 2007). Considering the important role of the hippocampus in epileptogenesis, researchers think that depotentiation or depression induced by LFS in structures of the hippocampus may have a role in its antiepileptogenic effects (Dudek \& Bear, 1992; Kulla, Reymann, \& Manahan-Vaughan, 1999). Besides, LFS inhibits seizures through the activation of GABA-benzodiazepine receptors and subsequent GABA release (López-Meraz, Neri-Bazán, \& Rocha, 2004). On the other hand, sodium valproate can increase the GABA level by inhibiting degradation as well as increasing its synthesis from glutamic acid (Löscher, Rundfeldt, \& Hönack, 1993; Rohlfs, et al., 1996; Töllner, et al., 2011). Both mentioned mechanisms may be considered as the basic mechanism for the positive interaction between LFS and valproate to suppress seizure severity in our study.

In summary, the combination of LFS with sodium valproate improved seizure activity during CA1 hippocampal kindling. Therefore, it can be considered a good therapy method for drug-resistant epileptic patients. However, more studies are required to confirm this finding.

\section{Ethical Considerations}

\section{Compliance with ethical guidelines}

All ethical principles are considered in this article. The researchers observed the principles of the Helsinki Declaration and the principles of using laboratory animals as suggested in the National Institutes of Health Guide for Care and Use of Laboratory Animals over the course of the study.

\section{Funding}

This research was supported by Shahid Chamran University of Ahvaz (Grant No.: 96.302.16670.1396.3.6).

\section{Authors' contributions}

All authors equally contributed to preparing this article.

\section{Conflict of interest}

The authors declared no conflicts of interest.

\section{Acknowledgments}

We gratefully acknowledge Shahid Chamran University of Ahvaz for supporting this study.

\section{References}

Asgari, A., Semnanian, S., Atapour, N., Shojaei, A., Moradi, H., \& Mirnajafi-Zadeh, J. (2014). Combined sub- threshold dosages of phenobarbital and low-frequency stimulation effectively reduce seizures in amygdala-kindled rats. Neurological Sciences, 35(8), 1255-60. [DOI:10.1007/s10072-0141693-9] [PMID]

Bonansco, C., \& Fuenzalida, M. (2016). Plasticity of hippocampal excitatory-inhibitory balance: Missing the synaptic control in the epileptic brain. Neural Plasticity, 2016, 8607038. [DOI:10.1155/2016/8607038] [PMID] [PMCID]

Carrington, C. A., Gilby, K. L., \& McIntyre, D. C. (2007). Effect of focal low-frequency stimulation on amygdalakindled afterdischarge thresholds and seizure profiles in fast-and slow-kindling rat strains. Epilepsia, 48(8), 1604-13. [DOI:10.1111/j.1528-1167.2007.01077.x] [PMID]

Chiu, C. T., Wang, Z., Hunsberger, J. G., \& Chuang, D. M., \& Sibley, D. R. (2013). Therapeutic potential of mood stabilizers lithium and valproic acid: Beyond bipolar disorder. Pharmacological Reviews, 65(1), 105-42. [DOI:10.1124/ pr.111.005512] [PMID] [PMCID]

Cuellar-Herrera, M., Peña, F., Alcantara-Gonzalez, D., NeriBazan, L., \& Rocha, L. (2010). Antiepileptic drugs combined with high-frequency electrical stimulation in the ventral hippocampus modify pilocarpine-induced status epilepticus in rats. Epilepsia, 51(3), 432-7. [DOI:10.1111/ j.1528-1167.2009.02315.x] [PMID]

Dudek, S. M., \& Bear, M. F. (1992). Homosynaptic long-term depression in area CA1 of hippocampus and effects of $\mathrm{N}$ methyl-D-aspartate receptor blockade. Proceedings of the National Academy of Sciences of the United States of America, 89(10), 4363-7. [DOI:10.1073/pnas.89.10.4363] [PMID] [PMCID]

Goldenberg, M. M. (2010). Overview of drugs used for epilepsy and seizures: Etiology, diagnosis, and treatment. $P \mathcal{E}$ 
T: A Peer-Reviewed Journal for Formulary Management, 35(7), 392-415. [PMID] [PMCID]

Hoffmann, J., Akerman, S., \& Goadsby, P. J. (2014). Efficacy and mechanism of anticonvulsant drugs in migraine. Expert Review of Clinical Pharmacology, 7(2), 191-201. [DOI:10.1586/ 17512433.2014.885835] [PMID]

Kalynchuk, L. E. (2000). Long-term amygdala kindling in rats as a model for the study of interictal emotionality in temporal lobe epilepsy. Neuroscience \& Biobehavioral Reviews, 24(7) 691-704. [DOI:10.1016/s0149-7634(00)00031-2] [PMID]

Kandratavicius, L., Balista, P. A., Lopes-Aguiar, C., Ruggiero, R. N., Umeoka, E. H., \& Garcia-Cairasco, N., et al. (2014) Animal models of epilepsy: Use and limitations. Neuropsychiatric Disease and Treatment, 10, 1693-705. [DOI:10.2147/ NDT.S50371] [PMID] [PMCID]

Kerrigan, J. F., Litt, B., Fisher, R. S., Cranstoun, S., French, J. A., \& Blum, D. E., et al. (2004). Electrical stimulation of the anterior nucleus of the thalamus for the treatment of intractable epilepsy. Epilepsia, 45(4), 346-54. [DOI:10.1111/j.00139580.2004.01304.x] [PMID]

Kile, K. B., Tian, N., \& Durand, D. M. (2010). Low frequency stimulation decreases seizure activity in a mutation model of epilepsy. Epilepsia, 51(9), 1745-53. [DOI:10.1111/j.15281167.2010.02679.x] [PMID] [PMCID]

Krauss, G. L., \& Sperling, M. R. (2011). Treating patients with medically resistant epilepsy. Neurology: Clinical Practice, 1(1), 14-23. [DOI:10.1212/CPJ.0b013e31823d07d1] [PMID] [PMCID]

Kuang, Y., Xu, C., Zhang, Y., Wang, Y., Wu, X., \& Wang, Y., et al. (2017). Low-frequency stimulation of the primary focus retards positive transfer of secondary focus. Scientific Reports, 7(1), 345. [DOI:10.1038/s41598-017-00479-z] [PMID] [PMCID]

Kulla, A., Reymann, K. G., \& Manahan-Vaughan, D. (1999). Time-dependent induction of depotentiation in the dentate gyrus of freely moving rats: Involvement of group 2 metabotropic glutamate receptors. European Journal of Neuroscience, 11(11), 3864-72. [DOI:10.1046/j.1460-9568.1999.00807.x] [PMID]

López-Meraz, M. L., Neri-Bazán, L., \& Rocha, L. (2004). Low frequency stimulation modifies receptor binding in rat brain. Epilepsy Research, 59(2-3), 95-105. [DOI:10.1016/j.eplepsyres.2004.02.005] [PMID]

Löscher, W. (1989). Valproate enhances GABA turnover in the substantia nigra. Brain Research, 501(1), 198-203. [DOI:10.1016/0006-8993(89)91044-5]

Löscher, W. (1999). Valproate: A reappraisal of its pharmacodynamic properties and mechanisms of action. Progress in Neurobiology, 58(1), 31-59. [DOI:10.1016/s03010082(98)00075-6] [PMID]

Löscher, W. (2002). Basic pharmacology of valproate. CNS Drugs, 16(10), 669-94. [DOI:10.2165/00023210-20021610000003] [PMID]

Löscher, W., Potschka, H., Wlaź, P., Danysz, W., \& Parsons, C. G. (2003). Are neuronal nicotinic receptors a target for antiepileptic drug development? Studies in different seizure models in mice and rats. European Journal of Pharmacol- ogy, 466(1-2), 99-111. [DOI:10.1016/s0014-2999(03)01542-5] [PMID]

Löscher, W., Rundfeldt, C., \& Hönack, D. (1993). Pharmacological characterization of phenytoin-resistant amygdala-kindled rats, a new model of drug-resistant partial epilepsy. Epilepsy Research, 15(3), 207-19. [DOI:10.1016/09201211(93)90058-F]

Mantovani, M., Moser, A., Haas, C. A., Zentner, J., \& Feuerstein, T. J. (2009). GABAA autoreceptors enhance GABA release from human neocortex: Towards a mechanism for High-Frequency Stimulation (HFS) in brain? NaunynSchmiedeberg's Archives of Pharmacology, 380(1), 45-58. [DOI:10.1007/s00210-009-0410-3] [PMID]

Mohammad-Zadeh, M., Mirnajafi-Zadeh, J., Fathollahi, Y., Javan, M., Ghorbani, P., \& Sadegh, M., et al. (2007). Effect of low frequency stimulation of perforant path on kindling rate and synaptic transmission in the dentate gyrus during kindling acquisition in rats. Epilepsy Research, 75(2-3), 15461. [DOI:10.1016/j.eplepsyres.2007.05.003] [PMID]

Paxinos, G., \& Watson, C. (1998). The rat in stereotaxic coordinates. Cambridge, MA: Academic Press. https://books. google.com/books?id=9nXEtwEACAAJ\&dq

Pitkänen, A., Löscher, W., Vezzani, A., Becker, A. J., Simonato, M., \& Lukasiuk, K., et al. (2016). Advances in the development of biomarkers for epilepsy. The Lancet Neurology, 15(8) 843-56. [DOI:10.1016/S1474-4422(16)00112-5]

Racine, R. J. (1972). Modification of seizure activity by electrical stimulation: II. Motor seizure. Electroencephalography and Clinical Neurophysiology, 32(3), 281-94. [DOI:10.1016/00134694(72)90177-0] [PMID]

Rohlfs, A., Rundfeldt, C., Koch, R., \& Löscher, W. (1996). A comparison of the effects of valproate and its major active metabolite E-2-en-valproate on single unit activity of substantia nigra pars reticulata neurons in rats. Journal of Pharmacology and Experimental Therapeutics, 277(3), 1305-14. [PMID]

Schrader, L. M., Stern, J. M., Wilson, C. L., Fields, T. A., Salamon, N., \& Nuwer, M. R., et al. (2006). Low frequency electrical stimulation through subdural electrodes in a case of refractory status epilepticus. Clinical Neurophysiology, 117(4), 781-8. [DOI:10.1016/j.clinph.2005.12.010] [PMID]

Schulze-Bonhage, A. (2017). Brain stimulation as a neuromodulatory epilepsy therapy. Seizure, 44, 169-75. [DOI:10.1016/j. seizure.2016.10.026] [PMID]

Telfeian, A., Celix, J., \& Dichter, M, (2005). Molecular mechanisms of epilepsy and gene therapy. In A. Freese, F. A. Simeone, P. Leone, C. Janson (Eds.), Principles of molecular neurosurgery. Progress in neurological surgery (pp. 169-201). Vol. 18. Basel: Karger. [DOI:10.1159/000084461]

Toibaro, L., Pereyra, M., Pastorino, J., Smigliani, A., Ocariz, F., \& Ortmann, G., et al. (2012). Effect of unilateral low-frequency stimulation of hippocampus on rapid kindling-induced seizure development in rats. Neuroscience and Medicine, 3(2), 174-80. [DOI:10.4236/nm.2012.32022]

Töllner, K., Wolf, S., Löscher, W., \& Gernert, M. (2011). The anticonvulsant response to valproate in kindled rats is correlated with its effect on neuronal firing in the substantia nigra pars reticulata: A new mechanism of pharmacoresist- 
ance. Journal of Neuroscience, 31(45), 16423-34. [DOI:10.1523/ JNEUROSCI.2506-11.2011] [PMID] [PMCID]

Vonck, K., Boon, P., Achten, E., De Reuck, J., \& Caemaert, J. (2002). Long-term amygdalohippocampal stimulation for refractory temporal lobe epilepsy. Annals of Neurology, 52(5), 556-65. [DOI:10.1002/ana.10323] [PMID]

West, S., Nolan, S. J., \& Newton, R. (2016). Surgery for epilepsy: A systematic review of current evidence. Epileptic Disorders, 18(2), 113-21. [DOI:10.1684/epd.2016.0825] [PMID]

Whitlow, R. D., Sacher, A., Loo, D. D., Nelson, N., \& Eskandari, S. (2003). The anticonvulsant valproate increases the turnover rate of gamma-aminobutyric acid transporters. The Journal of Biological Chemistry, 278(20), 17716-26. [DOI:10.1074/ jbc.M207582200] [PMID]

Zalkhani, R., Moazedi, A. A., Ghotbeddin, Z., \& Pourmahdi Borujeni, M. (2020). The therapeutic effects of low-frequency electrical stimulations adjunct to sodium valproate on seizure and behaviors. Basic and Clinical Neuroscience, 11(1), 5968. [DOI:10.32598/bcn.9.10.280] [PMID] [PMCID] 
This Page Intentionally Left Blank 